\title{
SÍNDROME DE BURNOUT EM ESTUDANTES UNIVERSITÁRIOS: um olhar sobre as investigações
}

\author{
Íris Dantas da Mota' \\ Gelcemar Oliveira Farias ${ }^{2}$ \\ Rudney da Silva ${ }^{3}$ \\ Alexandra Folle $e^{4}$
}

\section{RESUMO $^{5}$}

O exagero e a exacerbação de tarefas acadêmicas, aliados à conciliação de estudo e trabalho, podem levar estudantes a apresentarem alguns sintomas da Síndrome de Burnout. Neste contexto, esta revisão de literatura visa analisar publicações que abordem a Síndrome de Burnout em estudantes universitários. Foram consultados periódicos, dissertações, teses, livros e capítulos de livro, ligados às áreas da Educação e da Educação Física, que trouxessem maiores subsídios para o estudo desta temática. As informações obtidas na literatura revelam a demanda de estudos centrados em estudantes da área da Saúde e de reflexões sobre os fatores de risco, possíveis de desencadear a Síndrome de Burnout, durante a formação inicial. O período de estágios curriculares simboliza a etapa decisiva do curso para desencadear os sintomas da síndrome, por deparar-se o futuro profissional com situações reais em que problemas, dificuldades e limitações da prática laboral ficam evidentes.

Palavras-chave: Esgotamento Profissional. Universidades. Educação Física e Treinamento. Estudantes.

1 Mestranda em Ciências do Movimento Humano. Universidade do Estado de Santa Catarina (UDESC). Florianópolis/Santa Catarina, Brasil. E-mail: Irisdantas83@gmail.com

2 Doutora em Educação Física. Professora da Universidade do Estado de Santa Catarina (UDESC). Florianópolis/ Santa Catarina, Brasil. E-mail: fariasgel@hotmail.com

3 Doutor em Engenharia de Produção. Professor da Universidade do Estado de Santa Catarina (UDESC). Florianópolis/Santa Catarina, Brasil. E-mail: rudney.silva@udesc.br

4 Doutora em Educação Física. Professora da Universidade do Estado de Santa Catarina (UDESC). Florianópolis/ Santa Catarina, Brasil. E-mail: afolle_12@hotmail.com

5 Os autores declaram não haver conflitos de interesse em relação a este estudo.

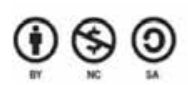




\title{
BURNOUT IN COLLEGE STUDENTS: a considered of investigations
}

\begin{abstract}
Overstatment and exacerbation of academic assignments, integrated with employment and study, can manifest some symptoms of Burnout Syndrome at academic students. In this context, this theoretical essay aims analyze the literature around the Burnout Syndrome in university students. Journals in Education and Physical Education area, dissertations, theses, books and book chapters were researched to bring greater benefits for reading on the subject. The literature information show increased demand for focused studies on students of health area and risk factors reflections, are possibly trigguing Burnout Syndrome during initial training. In addition, the period of traineeships symbolizes the decisive stage of the course to initiate the symptoms of the syndrome, where the future professional face real situations of problems, difficulties and limitations of labor practice are evident.
\end{abstract}

Keywords: Burnout. University. Physical Education and Training. Students.

\section{SÍNDROME DE BURNOUT EM ESTUDIANTES UNIVERSITARIOS: um ensayo teórico}

\section{RESUMEN}

La exageración y exacerbación de las tareas académicas, junto con la conciliación del trabajo y el estudio, pueden hacer que los estudiantes muestran algunos síntomas del síndrome de desgaste. En este contexto, el presente ensayo teórico tiene como objetivo analizar la literatura alrededor del Síndrome de Burnout en estudiantes universitarios. Ellos fueron consultados revistas en el campo de la educación y la educación física, disertaciones, tesis, libros y capítulos de libros que podrían traer mayores beneficios para leer sobre el tema. La información obtenida en la literatura muestran una mayor demanda de estudios concentrados en el área de salud de los estudiantes y reflexiones sobre los factores de riesgo, es posible síndrome de agotamiento de disparo durante el entrenamiento inicial. Además, el período de prácticas simboliza la etapa decisiva del curso para desencadenar los síntomas del síndrome, el futuro profesional con situaciones reales que encuentran en los problemas, las dificultades y limitaciones de la práctica laboral son evidentes.

Palabras clave: Agotamiento Profesional. Universidad. Educación y Entrenamiento Físico. Estudiantes 


\section{INTRODUÇÃO}

As atuais exigências profissionais têm elevado a incidência de pessoas acometidas pela Síndrome de Burnout. Este fenômeno tem gerado preocupação em profissionais de diversas áreas, pois afeta a vida pessoal e profissional dos indivíduos. As investigações sobre a Síndrome de Burnout são importantes para dimensionar os fatores que promovem seu surgimento, contribuindo para a compreensão das relações sociais atuais que podem revelar indicadores da síndrome, inclusive durante a formação universitária.

A base teórica da Síndrome de Burnout foi consolidada por Maslach e Jackson (1981), os quais expõem a definição multifatorial que envolve três componentes: exaustão emocional, despersonalização, realização profissional. A exaustão emocional é caracterizada por um sentimento muito forte de tensão emocional que produz sensação de esgotamento, de falta de energia e de recursos emocionais para lidar com as rotinas da prática profissional, representando a dimensão individual da síndrome. A despersonalização é resultado do desenvolvimento de sentimentos e de atitudes negativas, por vezes, indiferentes e cínicas, em relação àquelas pessoas que entram em contato direto com o profissional e que são sua demanda e seu objeto de trabalho. A falta de realização profissional, que se caracteriza pela tendência de estar insatisfeito com as condições que afetam as habilidades interpessoais relacionadas com a prática profissional, influenciando, diretamente, a forma de atendimento e de contato com as pessoas, bem como com a organização do trabalho.

Maslach, Schaufeli e Leiter (2001) explicam que os sintomas da síndrome relacionam cinco elementos comuns, centrados na predominância da exaustão mental e emocional; da fadiga e da depressão; da ênfase nos sintomas comportamentais e mentais interligados ao trabalho (manifestando-se em pessoas que não sofriam de distúrbios psicopatológicos antes do surgimento da síndrome); da diminuição da efetividade; do desempenho no trabalho em virtude de atitudes e comportamentos negativos.

Benevides-Pereira (2003), ao abordar o estado da arte da Síndrome de Burnout no Brasil, expressa que o estudo pioneiro foi o de Freudenberger, que a configurou como um estado relacionado com as experiências de esgotamento e decepção, bem como com a perda do interesse pela atividade de trabalho, manifestando-se em profissionais que, em seu dia a dia, trabalham diretamente com pessoas. Este fato gera determinada preocupação dos pesquisadores em relação à síndrome, motivando novos estudos direcionados a diferentes áreas de conhecimento.

Na literatura que trata sobre esta temática, são investigados profissionais de diversas áreas, entre eles, enfermeiros (GALINDO et al., 2012), médicos (ARDILA, 2007), fonoaudiólogos (NÓBREGA; BARBOZA, 2014), professores (MELO; REGO et al., 2015) e atletas (PIRES et al., 2012), os quais revelam alta exaustão emocional e baixa realização no contexto de trabalho. Estudos centrados nos professores são encontrados em larga escala na literatura brasileira, possibilitando redimensionar a atuação destes profissionais da Educação, bem como reestruturar o ambiente de trabalho, os processos de avaliação e sua qualidade de vida (CARLOTTO, 2003; CARLOTTO; CÂMARA 2007; BATISTA et al., 2010) 
Diante deste cenário, investigações em torno da Síndrome de Burnout em estudantes universitários têm sido desenvolvidas, de modo a entender como os processos de ensino-aprendizagem influenciam o bem-estar desta população em fase de formação profissional. Além disso, a presença do estudante trabalhador tem se intensificado, indicando a necessidade de maior aprofundamento do conhecimento sobre a Síndrome de Burnout nesta população.

Atualmente, são evidenciadas constantes alterações no contexto da formação inicial, relacionadas com as tecnologias de comunicação e de informação, bem como com as próprias demandas formativas da universidade e as perspectivas pedagógicas. A inserção dos estudantes no contexto da pesquisa e da extensão, promovendo certo exagero e exacerbação de tarefas acadêmicas, tem sido responsável pelo surgimento de sintomas característicos da Síndrome de Burnout.

Ao considerar a relevância da compreensão dos fatores que podem acometer estudantes universitários com sintomas da síndrome, esta revisão de literatura analisa publicações que abordam a Síndrome de Burnout em estudantes universitários. Para operacionalizar essa investigação, foram consultados periódicos, dissertações, teses, livros e capítulos de livro, ligados às áreas da Educação e da Educação Física, que trouxessem maiores subsídios para o estudo desta temática. Ainda que tenha sido publicada uma gama de estudos sobre a Síndrome de Burnout, percebe-se que, até este momento, ainda são incipientes as investigações que tratam de estudantes universitários. O presente estudo se justifica por compreender que as demandas da formação inicial podem ser reestruturadas, ampliando as possibilidades de ação e promovendo a aquisição de conhecimento pelo estudante, sem que haja prejuízos para seu bem-estar e sua qualidade de vida. Consequentemente, ele poderá auxiliar no desenvolvimento de ações que permitam prevenir, abrandar ou mesmo cessar as sintomatologias da síndrome em sua fase mais inicial.

Este artigo caracteriza-se como uma revisão de literatura, realizada por meio de levantamentos bibliográficos e documentais, efetivados através de uma revisão sistematizada de fontes primárias e secundárias. A identificação e a seleção dos materiais teóricos utilizados orientaram-se pela temática categorial principal (Síndrome de Burnout) e secundária (formação universitária). Apesar de se ter priorizado a seleção e a análise de artigos científicos disponíveis na rede mundial de computadores, foram incluídos também dissertações e livros de base, essenciais à compreensão das bases teóricas da categoria principal deste estudo.

Na coleta das informações, foram selecionados periódicos de diferentes áreas do conhecimento, em especial, da área da Educação, encontrados em sítios eletrônicos de bibliotecas institucionais que forneciam acesso a teses e dissertações. Eles foram consultados até o mês de maio de 2016, nas línguas portuguesa, espanhola e inglesa, sem qualquer restrição de data de publicação. A análise e a discussão dos materiais processados, especialmente dos resultados dos estudos selecionados, foram executadas por meio de técnicas elementares de análise de conteúdo, buscando-se sua triangulação com a realidade da formação universitária nacional e internacional, bem como com a literatura de base acerca da Síndrome de Burnout. As contribuições teóricas são apresentadas em dois 
tópicos principais: o primeiro sobre a base teórica da Síndrome de Burnout; e o segundo sobre este fenômeno na formação universitária.

\section{Compreendendo a Síndrome de Burnout}

Na perspectiva de compreensão da base teórica da Síndrome de Burnout e da dimensão que ela assume na realidade de estudantes, trabalhadores, esportistas e outros grupos populacionais, buscou-se, através dos estudos de Maslach e Jackson (1981), Maslach e Florian (1988), Maslach, Schaufeli e Leiter (2001), Carlotto (2003), Gil-Monte (2003), Garcia e Benevides-Pereira (2003), Gil-Monte (2005), redimensionar o conhecimento agregado.

Diferentes terminologias são encontradas para referenciar a Síndrome de Burnout, de acordo com Benevides-Pereira (2003), citam-se: Síndrome de Queimar-se no Trabalho, Síndrome de Esgotamento Profissional, Neurose Profissional. Conforme Maslach e Jackson (1981), Burnout é uma síndrome de exaustão emocional que acomete um grande número de trabalhadores no que tange as variáveis pessoais, sociais e institucionais. A teoria revela que os trabalhadores, que apresentam a síndrome, encontram-se com seus recursos emocionais esgotados e desenvolvem atitudes cínicas e sentimentos negativos para lidar com suas práticas profissionais. Ao mesmo tempo em que manifestam sentimentos negativos em relação às pessoas que os circundam, estes trabalhadores fazem uma avaliação negativa de si mesmo, manifestando, consequentemente, insatisfação com sua atividade.

O desdobramento do estudo de Maslach e Jackson (1981) foi, posteriormente, reconhecido como a base da teoria, instigando investigações sobre diferentes ocupações. Maslach e Florian (1988), ao investigarem profissionais que trabalham com reabilitação, caracterizaram a síndrome no que se refere à exaustão emocional, à despersonalização e à baixa realização profissional. Tais autores ampliaram o conceito apresentado por Maslach e Jackson (1981), explicitando que a exaustão é sinalizada pelo esgotamento dos recursos emocionais; pela despersonalização, com desenvolvimento de atitudes negativas em relação às pessoas com quem trabalham ou têm contato profissional; pela baixa realização profissional, refletida no sentimento de infelicidade consigo mesmo e com suas relações no trabalho.

Maslach, Schaufeli e Leiter (2001) definiram a Síndrome de Burnout sob o enfoque social. Eles estabeleceram conexões sólidas entre as dificuldades encontradas no trabalho e algumas características pessoais, determinadas como fatores preponderantes, reconhecendo a síndrome como um fenômeno da era atual. O conceito de Síndrome de Burnout está centrado na definição psicológica em resposta a estressores interpessoais crônicos do emprego. A resposta prolongada e crônica da síndrome ocorre em três dimensões, sendo a exaustão intensa representada pelas dimensões de estresse ou de despersonalização ou por sentimentos de cinismo. Estes representam tanto a dimensão do contexto interpessoal, ou seja, uma resposta negativa ao trabalho, como a de realização pessoal, expressa pela percepção de incompetência, pela falta de satisfação, pela pouca produtividade no trabalho. 
A Síndrome de Burnout, na perspectiva de Carlotto (2003), está associada a disfunções pessoais no relacionamento entre o homem e seu trabalho. Em decorrência deste desequilíbrio laboral, problemas psicológicos e físicos podem ser desencadeados no trabalhador, evidenciando sintomas de estresse laboral que, com o passar dos anos, podem ocasionar o surgimento da Síndrome de Burnout. Alguns sintomas típicos são relatados por Benevides-Pereira (2002), como sintomatologias que afetam o indivíduo, nas esferas física, psíquica, comportamental e defensiva, dentre as quais se destacam: fadiga constante e progressiva; distúrbios do sono; dores musculares; irritabilidade; perda de iniciativa; incapacidade para relaxar; falta de atenção e de concentração; alterações da memória; impaciência; tendência ao isolamento; absenteísmo; perda de interesse pelo trabalho.

Ao compreender a síndrome como um processo psicossocial, entende-se que manifestação dos sintomas depende de características individuais e ambientais. $\mathrm{O}$ autor acima citado percebe a atividade física como uma estratégia de enfrentamento destes sintomas, no que tange a esfera individual, contribuindo para a melhora da saúde em geral e do desempenho das funções ocupacionais.

Gil-Monte (2003) compreende o Burnout como a síndrome de queimar por meio do trabalho, estabelecendo relações com a resposta ao estresse crônico de profissionais, como médicos um dos fatores relevantes para o desenvolvimento de sintomas da síndrome relacionados ao ambiente laboral. Ela também é caracterizada como uma degradação cognitiva que ocasiona perda de motivação e baixa realização pessoal no trabalho, suscitando atitudes negativas, tais como: comportamentos de indiferença; frieza; distanciamento. Essas reações podem, em certas ocasiões, vir acompanhadas de sentimentos de culpa.

A expressão Burnout é uma palavra inglesa, utilizada para designar aquilo que deixou de funcionar por exaustão de energia e em decorrência da má adaptação do indivíduo a um trabalho prolongado e muito estressante (GARCIA; BENEVIDES-PEREIRA, 2003). Os sintomas da síndrome decorrem de um trabalho que demanda cargas de tensão, gerando exaustão física, psíquica e emocional. Sentimentos de frustação em relação a si e ao trabalho são manifestados, porém a instalação da síndrome acontece de modo silencioso e progressivo. Em alguns casos, o profissional só percebe que está sendo por ela acometido, quando ela passa a impactar e a afetar sua vida pessoal.

De maneira geral, o sujeito acometido pela Síndrome de Burnout afasta-se das relações sociais, devido aos transtornos mentais que ela provoca, o que pode, de algum modo, gerar os conflitos com seus pares, reforçando o distanciamento afetivo (BENEVIDES-PEREIRA, 2002). Neste caso, a família e o grupo de trabalho passam a sofrer as consequências. Como não há o conhecimento declarado do que está afetando aquele indivíduo, as relações tendem a se enfraquecer (FOGAÇAetal., 2008). Trigo, Teng e Hallak (2007, p. 230), ao concluírem o estudo, revelam que os dados encontrados emitem "[...] que o Burnout interfere nos níveis institucional, social e pessoal".

Na averiguação da Síndrome de Burnout nas populações investigadas, o instrumento Maslach Burnout Inventory (MBI), construído por Maslach e Jackson (1981), foi o primeiro a reportar a coleta de informações com profissionais sobre a Síndrome de Burnout, abrangendo as dimensões que a caracterizam, como intensa exaustão emocional 
e esgotamento, alta despersonalização ou cinismo; baixa realização pessoal no ambiente de trabalho. Mesmo com valores adequados de fidedignidade e validade, Gil-Monte (2005) relatou insuficiências psicométricas, ao verificar a validação fatorial e a consistência interna do $\mathrm{MBI}$. A análise destas insuficiências resultou na elaboração do instrumento de avaliação alternativo Cuestionario para La Evoluación del Síndrome de Quemarse por El Trabajo(CESQT).

O CESQT é formado por quatro dimensões: ilusão pelo trabalho; desgaste psíquico; indolência; culpa. A ilusão pelo trabalho é definida como a expectativa do indivíduo em alcançar determinadas metas laborais, pois isso supõe uma fonte de realização pessoal e profissional. O desgaste psíquico é compreendido como a presença do esgotamento emocional e físico, decorrente da atividade de trabalho, tendo em vista a necessidade de se relacionar diariamente com pessoas que possuem ou geram problemas. A indolência é reconhecida como a presença de atitudes negativas de indiferença e cinismo frente aos clientes da organização. A culpa é determinada como a ocorrência de sentimentos de culpa pelo comportamento e pelas atitudes negativas desenvolvidas no trabalho, principalmente, frente às pessoas com as quais o trabalhador deve se relacionar profissionalmente.

Ao observar as duas teorias sobre a Síndrome de Burnout, percebem-se similaridades no que tange suas dimensões, no entanto Gil-Monte (2005) acrescentou a dimensão culpa não retratada por Maslach e Jackson (1981). Com o avanço dos estudos sobre o tema, a validação do instrumento tornou-se necessária, a fim de atender os critérios éticos deliberados pelos órgãos responsáveis. Com interesse de investigar a síndrome em diferentes populações, Pires, Brandão e Silva (2006) validaram o MBI, alterando sua nomenclatura para Athlete Burnout Questionnaire, na versão brasileira com atletas. Schaufeli et al.(2002) validaram o instrumento com estudantes universitários o renomeando de Maslach Burnout Inventory Student Survey. Carlotto e Câmara (2006) traduziram e adaptaram tal instrumento para a língua portuguesa, para aplicá-lo em estudos com estudantes universitários brasileiros. Gil-Monte, Carlotto e Câmara (2010) realizaram o processo de validação do questionário Cuestionario para La Evoluación del Síndrome de Quemarse por El Trabajo para a versão brasileira com professores.

Borges e Carlloto (2004), Martinez e Pinto (2005) e Carlotto, Nakamura e Câmara (2006), ao investigarem a síndrome em estudantes de cursos de Ensino Superior, tomaram, como base teórica, Schafeliet al.(2002), os quais investigaram a presença das três dimensões da Síndrome de Burnout (exaustão emocional, descrença, eficácia profissional).

\section{Contextualizando a Síndrome de Burnout em estudantes universitários}

O surgimento dos sintomas da Síndrome de Burnout não se limita apenas a profissionais formados. No decorrer da formação inicial, os estudantes, quando submetidos a cargas horárias elevadas e estressantes (CHRISTOFOLETTI et al., 2007), associadas a estágios curriculares e práticas supervisionadas, apresentam sinais de exaustão física e emocional (RUDNICKI; CARLOTTO, 2007). Investigações realizadas com acadêmicos 
de diversos cursos de graduação confirmaram o aparecimento de sinais da Síndrome de Burnout em universitários, que se encontram em diferentes etapas da formação inicial, como fator primordial para o distanciamento dos estudos e o comprometimento de seu sentimento de eficácia profissional (BORGES; CARLOTTO, 2004; CHRISTOFOLETTI et al., 2007; RUDNICKI; CARLOTTO, 2007; TARNOWSKI; CARLOTTO, 2007; BARBOZA; BERESIN, 2007; CARLOTTO;CÂMARA, 2008; CARLOTTO et al., 2010; CAMPOS et al., 2012; TOMASCHEWSKI-BARLEM et al., 2013; GUIMARÃES, 2014).

Pesquisas com estudantes da área da saúde foram as mais encontradas, durante extensa busca na literatura. Cristofoletti et al. (2007) investigaram estudantes de Fisioterapia e encontraram escores moderados nos indicadores exaustão emocional e despersonalização, indicando sinais de estresse condizentes com a síndrome. Os mesmos autores relatam que o estágio, realizado na fase investigada, contribuiu intensamente para o surgimento dos sintomas, pois os acadêmicos, além de experimentarem a prática profissional, ficam submetidos às exigências da supervisão e da avaliação docente.

Na investigação que abordou alunos que cursam Psicologia, Carlottoet al. (2010) verificaram que, no início da graduação, as leituras técnicas e os estudos de caso analisados em sala de aula podem impulsionar alguns estudantes a desenvolverem sintomas da Síndrome de Burnout. Nos últimos anos, os estágios e o contato com os pacientes influenciam o nível de ansiedade causada pela exigência de assumir uma postura profissional e de integrar a teoria com a prática. Os citados autores descrevem a formação do aluno de Psicologia como uma vivência de momentos de ansiedade, causada pela carga emocional desencadeada pelo curso.

Ao avaliar a existência de valores significativos nas dimensões de Burnout, em estudantes do início e do final do curso de Psicologia, Tarnowski e Carlotto (2007) identificaram que os alunos de final de curso exibem diferença estatisticamente significativa com relação à dimensão de exaustão emocional, apresentando maior sentimento de desgaste do que os estudantes de início de curso. Nas dimensões de descrença e eficácia profissional, não foram identificadas diferenças significativas.

Barboza e Beresin (2007) analisaram a ocorrência da Síndrome de Burnout em graduandos de Enfermagem, verificando elevado índice na dimensão que trata da realização profissional e indicando certa desmotivação relacionada com sua escolha profissional, haja vista ter sido percebido valores médios/moderados nas dimensões exaustão emocional e despersonalização. Posteriormente à realização deste estudo citado, Tomaschewski-Barlemet al. (2013) efetivaram uma investigação de cunho qualitativo com estudantes de Enfermagem, diagnosticando que fatores como avaliação constante dos docentes e atividades extraclasse desencadeiam a exaustão emocional, fato que requer a atenção das instituições de ensino superior.

O estudo de Tomaschewski-Barlemet al. (2013)revelou a incidência das três dimensões da Síndrome de Burnout, associadas às especificidades das situações vivenciadas pelos estudantes universitários: elevada carga horária das disciplinas; atividades extraclasse e extracurriculares; percepção de estarem permanentemente sendo avaliados pelos docentes; dicotomia entre teoria e prática; falta de acolhimento por parte das diferentes equipes de 
saúde, durante as atividades práticas e os estágios; contato frequente com situações de sofrimento; falta de reconhecimento e de valorização da Enfermagem e de identificação com as atividades da profissão. Estes fatores estão associados, principalmente, à exaustão emocional, contribuindo para o distanciamento dos estudos e o comprometimento do sentimento de eficácia profissional.

O estudo realizado por Cecil, Hart e Laidlaw (2014), com estudantes de Medicina de duas universidades do Reino Unido, verificou a associação existente entre os níveis de atividade física e a ocorrência da Síndrome de Burnout, identificando a influência positiva da atividade física para prevenir o surgimento da síndrome, principalmente, no que tange a exaustão emocional. A prática de hábitos saudáveis foi considerada, no estudo em tela, fator relevante para a prevenção das sintomatologias da síndrome que afetam os estudantes durante o processo da formação inicial.

Carlotto, Nakamura e Câmara (2006) investigaram a Síndrome de Burnout em estudantes universitários de todos os cursos da área da saúde de uma instituição universitária. Pelos resultados, identificaram índice médio/baixo de exaustão emocional; índice baixo em descrença; índice alto em eficácia profissional. Tais resultados não indicam, portanto, a presença da síndrome. Revelam, entretanto, a complexidade de fatores que podem se constituir em indicadores da Síndrome de Burnout ainda no processo de formação de profissionais da área da saúde, evidenciando a necessidade de se considerar que muitos dos fatores associados às três dimensões referem-se a contingências da vida estudantil. Em estudo com acadêmicos de Odontologia, Campos et al. (2012) estimaram a prevalência da Síndrome de Burnout, nestes estudantes, observando que a prevalência de sintomas foi alta, sendo significativa a relação entre ela e o desempenho no curso, o consumo de medicação devido aos estudos, o pensamento de desistir do curso.

Pelas investigações analisadas, torna-se perceptível que a Síndrome de Burnout afeta não somente aqueles que estão em situação de trabalho, mas também aqueles que ainda estão em processo de formação inicial. A demanda de estudos, associada à concepção de sociedade, a qual está cada vez mais em rápida transformação, tende a ser uma das características deste fato. O contexto vivenciado pelos estudantes universitários é diferente em várias situações, todavia os sentimentos e os sintomas são relativamente semelhantes aos dos profissionais no exercício de tarefas laborais. Situar as investigações com foco nos estudantes universitários torna-se, portanto, um desafio e exige o olhar tanto do profissional como dos gestores da universidade, possibilitando a construção de novos designers para a atuação e a intervenção profissionais.

Pela análise dos estudos mencionados, observa-se que a base teórica predominante é a de Maslach e Jackson (1981) e que o instrumento mais utilizado para a coleta das informações é o Maslach Burnout Inventory (MBI), construído por Maslach e Jackson (1981), na forma adaptada por Schaufeli et al.(2002), denominada Maslach Burnout Inventory/ Student Survey (MBI-SS). O instrumento consiste de 15 questões que se subdividem em três subescalas: exaustão emocional (5 itens); descrença (4 itens);eficácia profissional (6 itens). Todos os itens são avaliados pela frequência, em uma escala de 0 a 6 , sendo:0 (nunca); 1 (uma vez ao ano ou menos); 2 (uma vez ao mês ou menos); 3 (algumas vezes ao mês); 4 (uma vez por semana); 5 (algumas vezes por semana); 6 (todos os dias). 
A teoria sobre a Síndrome de Burnout, quando adaptada para investigação em estudantes, constitui-se das seguintes dimensões: exaustão emocional, caracterizada pelo sentimento de estar exausto em virtude das exigências do estudo; descrença, entendida como o desenvolvimento de uma atitude cínica e distanciada com relação ao estudo; ineficácia profissional, caracterizada pela percepção de estarem sendo incompetentes como estudantes (CARLOTTO; NAKAMURA; CÂMARA, 2006). Percebe-se que a prevalência da síndrome em estudantes, especificamente da área da saúde, é alta, sendo significativa a relação entre os sintomas da síndrome e o desempenho dos universitários durante o curso, ocorrendo consumo de medicação devido à exigência dos estudos e sendo frequente o pensamento de desistir. A experiência profissional advinda dos estágios também apresenta importante relação com a presença das dimensões relacionadas à síndrome. Nota-se que, além dos estressores característicos do ensino, a atuação direta com pessoas é um fator relevante e diferenciado para desencadear a síndrome.

Considerando que os indivíduos utilizam suas capacidades físicas e mentais para obter o progresso acadêmico requerido, assim como para a realização de atividades e o desenvolvimento de competências e habilidades, conclui-se que a exposição prolongada ao estresse crônico provoca o surgimento de Burnout em estudantes universitários. Estudar e investigar esse fenômeno, na fase da formação inicial, é importante para identificar, amenizar e/ou evitar o avanço da síndrome nos estudantes (GUIMARÃES, 2014).

\section{CONSIDERAÇÕES FINAIS}

Após a revisão de literatura e as considerações feitas sobre ela, conclui-se que a produção acadêmica e a produção científica têm contribuído para o diagnóstico e para a mediação da intervenção dos sintomas da Síndrome de Burnout quer em profissionais que atuam com muitas pessoas, tais como os professores, os enfermeiros e os médicos, quer em estudantes, durante sua formação inicial.

Destaca-se que a maior demanda de estudos centra-se em trabalhadores de variadas áreas de conhecimento e em estudantes da área da saúde. Algumas pesquisas sugerem a reflexão sobre os fatores de risco para o desencadeamento da Síndrome de Burnout em estudantes universitários, durante a formação inicial. A limitação da análise é marcada pela incipiência de estudos publicados em língua portuguesa e pela realidade brasileira quanto a estudos sobre a Síndrome de Burnout. Este fato ressalta a relevância de novos ensinamentos com o intento de prevenir o aparecimento da síndrome, no decorrer da vida acadêmica, e estabelecer estratégias para evitar que os sintomas prossigam durante a vida profissional.

As pesquisas indicam que o período dos estágios curriculares constitui uma etapa que pode desencadear os sintomas da síndrome, pois os estudantes deparam-se com situações reais em que problemas, dificuldades, limitações da prática profissional ficam evidentes. $\mathrm{O}$ instrumento mais referenciado, na literatura, para analisar a Síndrome de Burnout em estudantes é o MBISS, o qual avalia como eles vivenciam seus estudos, de acordo com as três dimensões conceituais retratadas para entendimento da síndrome (exaustão emocional, despersonalização e baixa realização profissional). 
Estudos cuja temática é a Síndrome de Burnout e a população-alvo são estudantes universitários permitem a reflexão sobre a qualidade do ensino e seu incremento, auxiliando na orientação do currículo e de projetos pedagógicos, além de minimizar desconfortos ocasionados, no período da formação inicial, pela busca de melhor qualidade de vida e de melhor rendimento acadêmico. Embora professores também tenham sido investigados, destaca-se que a população de docentes universitários, ainda é pouco relatada, o que indica a relevância de novos estudos incluindo esta população.

Ressalta-se a importância de fomentar novas investigações em estudantes universitários, com o intuito de prevenir, neutralizar ou cessar as manifestações de Burnout em sua fase mais incipiente, para que as tarefas e as demandas de pesquisas sejam efetivadas com êxito e entusiasmo no decorrer da formação inicial.

Conquanto se percebam ações sociais, acadêmicas e científicas que contribuem para o tratamento da Síndrome de Burnout, ainda há necessidade de melhor compreender as estratégias que pares e familiares precisam estabelecer com aquele que é por ela acometido. É mister que haja a divulgação de dados fidedignos, para que se ampliem os estudos sobre o tema, transformando tais dados em conhecimento que revele mecanismos de ajuda para todas as pessoas acometidas da síndrome.

\section{REFERÊNCIAS}

ARDILA, E. Síndrome de Burnout y ladepresióndel médico de hoy. Acta Medicina Colombiana, Bogotá, v. 32, p. 173-174, 2007. Disponível em: http://www.redalyc. org/pdf/1631/163114146012.pdf. Acesso em: 20 abr. 2016.

BARBOZA, J.; BERESIN, R. A. A Síndrome de Burnout em graduandos de enfermagem. Einstein, São Paulo, v. 5, n. 3, p. 225-230, 2007. Disponível em: < http://apps.einstein. br/revista/arquivos/PDF/599-einstein.5.3.1.online.artigo.a\%20sindrome.225-230.pdf > . Acesso em: 22 mar. 2016.

BATISTA, J. B. V.; CARLOTTO, M.S.; COUTINHO, A.S., AUGUSTO, L.S.Prevalência da Síndrome de Burnoute fatores sociodemográficos e laborais em professores de escolas municipais da cidade de João Pessoa. Revista Brasileira de Epidemiologia, São Paulo, v. 13, n. 3, p. 502-512, 2010. Disponível em: < http://www.scielosp.org/pdf/rbepid/ v13n3/13.pdf > . Acesso em: 20 abr. 2016.

BENEVIDES-PEREIRA, A. M. T. Burnout: o processo de adoecer pelo trabalho. In: Benevides PAMT, organizador. Burnout: quando o trabalho ameaça o bem-estar do trabalhador. São Paulo: Editora Casa do Psicólogo; p.21-91. 9, 2002..Disponível em:https://books.google. com.br/books?id =EMnnJkIADqIC\&pg $=$ PA10\&lpg $=$ PA10\&dq $=$ Burnout: + quando $+\mathrm{O}+$ trabalho + amea $\% C 3 \% A 7 a+o+$ bem-estar + do + trabalhado\&source $=$ bl \&ots $=$ rcoxFV25 Pf\&sig = 5OoyJznl79RV35rlHN4Zd0xGj48\&hl = pt-BR\&sa $=$ X\&ved =0ahUKEwjdk_HR urTOAhVLgJAKHe6fDgsQ6AEIVjAI\#v = onepage $\& q=$ Burnout $\% 3 \mathrm{~A} \% 20$ quando $\% 20$ o\%20trabalho $\% 20$ amea $\%$ C3\%A7a $\% 200 \% 20$ bem-estar $\% 20$ do $\% 20$ trabalhado\&f $=$ false 
BENEVIDES-PEREIRA, A. M. T. O Estado da Arte do Burnoutno Brasil. Revista Eletrônica InterAçãoPsy, Maringá, v. 1, n. 1, p. 4 -11, 2003.Disponível em: <http://www. saudeetrabalho.com.br/download_2/burnout-benevides.pdf $>$. Acesso em: 25 mar. 2016.

BORGES, A. M. B.; CARLOTTO M. S. Síndrome de Burnout e fatores de estresse em estudantes de um Curso Técnico de Enfermagem. Aletheia, Canoas, n. 19, p. 45-56. 2004. Disponível em: < http://pepsic.bvsalud.org/pdf/aletheia/n19/n19a05.pdf>. Acesso em: 25 mar. 2016.

CAMPOS,J. A. D. B.; JORDANI, P. C.;ZUCOLOTO, M.L.; BONAFÉ, F.S.S.; MAROCO, J. Síndrome de Burnout tem graduandos de Odontologia. Revista Brasileira de Epidemiologia, São Paulo, v. 15, n. 1, p. 155 -65, 2012. Disponível em: < http://www.scielo.br/scielo.php?pid = S1415-790X2012000100014\&script = sci abstract\&tlng $=$ pt $>$. Acesso em: 25 mar. 2016.

CARLOTTO M. S.; CAMÂRA S. G. Preditores da Síndrome de Burnoutem professores. Revista Psicologia Escolar e Educacional, Uberlândia, v. 11, n. 1, p. 101-110, 2007. Disponível em: < http://www.scielo.br/pdf/pee/v11n1/v11n1a10.pdf>. Acesso em: 20 jun. 2016.

CARLOTTO M. S.; CAMÂRA S. G. Características psicométricas do MaslachBurnoutlnventory .StudentSurvey (MBI-SS) em estudantes universitários brasileiros.Psico-USF, Porto alegre, v. 11, n. 2, p. 167-173, 2006. Disponível em: < http://www.scielo.br/pdf/pusf/v11n2/ v11n2a05.pdf>. Acesso em: 20 jun. 2016.

CARLOTTO, M. S. Burnout e o trabalho docente: considerações sobre a intervenção. Revista Eletrônica InterAçãoPsy, Maringá, v. 1, n. 1, p. 12-18, 2003.Disponível em: < http://www.saudeetrabalho.com.br/download_2/burnout-professor.pdf >. Acesso em: 25 mar. 2016.

CARLOTTO, M. S.; CÂMARA, S.G.; OTTO, F., KAUFFMANN, P.Síndrome de Burnout e coping em estudantes de Psicologia. Boletim de Psicologia. São Leopoldo, v. 59, n. 131, p. 167-178, 2010. Disponível em: < http://pepsic.bvsalud.org/pdf/bolpsi/v59n131/ v59n131a04.pdf >. Acesso em: 25 mar. 2016.

CARLOTTO, M. S.; CÂMARA, S. G. Preditores da Síndrome de Burnout em estudantes universitários. Pensamiento Psicológico, v. 4, n. 10, p. 101-109, 2008. Disponível em: < http://www.redalyc.org/articulo.oa?id=80111670006>. Acesso em: 25 mar. 2016.

CARlOTTO, M. S.; NAKAMURA, A. P.; CÂMARA, S. G. Síndrome de Bburnoutem estudantes universitários da área da saúde. Psico, Porto Alegre, v. 37, n. 1, p. 57-62, 2006. Disponível em: < http://revistaseletronicas.pucrs.br/ojs/index.php/revistapsico/ article/view/1412>. Acessoem: 25 mar. 2016.

CECIL, J.; CALUM, M.H.; HART.J. ; LAIDLAW, A. Behaviour and burnout in medical students. JournalMedicalEducationOnline,v. 25, n. 19, p. 25209, 2014. Disponível em: < http://pepsic.bvsalud.org/pdf/bolpsi/v59n131/v59n131a04.pdf>. Acesso em: 13 fev. 2016.

CHRISTOFOLETTI, G.;TRELHA, C.S; GALERA, M. R.; FERACIN, M.A. Síndrome de Burnout em acadêmicos de Fisioterapia. Fisioterapia e Pesquisa, São Paulo, v.14, n. 2, p. 35-39, 2007. Disponível em: < http://pepsic.bvsalud.org/pdf/bolpsi/v59n131/v59n131a04. pdf $>$. Acesso em: 12 fev. 2016. 
FOGAÇA, M. C.; CARVALHO, W.B; CÍTERO, V.A.; NOGUEIRA-MARTINS, L.A. Fatores que tornam estressante o trabalho de médicos e enfermeiros em terapia intensiva pediátrica e neonatal: estudo de revisão bibliográfica. Revista Brasileira de Terapia Intensiva, São Paulo, v. 20, n. 3, p. 261- 266, 2008. Disponível em: < http://www.scielo.br/pdf/ rbti/v20n3/v20n3a09.pdf > . Acesso em: 15 fev. 2016.

GALINDO, R. H.; FELICIANO, K.V.O.; LIMA, R.A.S.; SOUZA, A.I. Síndrome de Burnout entre enfermeiros de um hospital geral da cidade do Recife. Revista da Escola de Enfermagem da USP, São Paulo, v. 46, n. 2, p. 420-427, 2012. Disponível em: < http:// www.scielo.br/pdf/reeusp/v46n2/a21v46n2.pdf > . Acesso em: 15 fev. 2016.

GARCIA L. P.; BENEVIDES-PEREIRA A. M. T. Investigando o Burnoutem professores universitários. Revista Eletrônica Interação, Maringá, v. 1, n 1, p. 76-89, 2003. Disponível em: <http://www.scielo.br/pdf/reeusp/v46n2/a21v46n2.pdf > . Acesso em: 15 fev. 2016.

GIL-MONTE, P. R. FactorialvalidityoftheMaslachBurnoutInventory (MBI-HSS) among Spanish professionals.Revista Saúde Pública, São Paulo, v. 39, n. 1, p. 1-8, 2005. Disponível em: $<$ http://www.scielo.br/pdf/rsp/v39n1/01.pdf>. Acesso em: 15 fev. 2016.

GIL-MONTE, P. R.; CARLOTTO, M. S.; CÂMARA, S. G. Validação da versão Brasileira do "Cuestionario para laEvaluacióndel Síndrome de Quemarse por elTrabajo" em professores.Revista de Saúde Pública, São Paulo, v. 44, n. 1, p. 140-147, 2010. Disponível em: <http://www.scielo.br/pdf/rsp/v44n1/15.pdf>. Acesso em: 15 fev. 2016.

GIL-MONTE, P. R.El Síndrome de Quemarse por elTrabajo (Síndrome de Burnout) em profesionales de Enfermería. Revista eletrônica Interação, Maringá, v. 1, n. 1, p. 19-33, 2003.Disponível em: <http://bvsper.paho.org/foro_hispano/BVS/bvsacd/cd49/artigo3. pdf > . Acesso em: 15 fev. 2016.

GUIMARÃES, E.R. A Síndrome de Burnout em estudantes de ciências contábeis: pesquisa na cidade de São Paulo. 2014. 103 f. Dissertação (Mestrado em Ciências Contábeis) - Centro de Ciências Contábeis, Fundação Escola de Comércio Álvaro Penteado, São Paulo, 2014. Disponível em: < http://tede.fecap.br:8080/jspui/bitstream/tede/541/1/ Erotides_Rocha_Guimaraes.pdf $>$. Acesso em: 15 fev. 2016.

MARTINEZ, I. M. M.; PINTO, A. M. Burnout enestudiantesuniversitarios de España y Portugal y surelaciónconvariables académicas. Aletheia,Canoas, n. 21, p. 21-30, 2005. Disponível em: < http://pepsic.bvsalud.org/pdf/aletheia/n21/n21a03.pdf > . Acessoem: 15 fev. 2016.

MASLACH, C.; FLORIAN, V. Burnout, job setting, and self-evaluation among rehabilitation counselors.Rehabilitation Psychology, New York, v. 33 n. 2, p. 85-93, 1988.Disponívelem: < http://www.scielo.br/pdf/rbem/v36n4/13.pdf>. Acessoem: 15 fev. 2016.

MASLACH, C.; JACKSON, S. E. MaslachBurnoutInventory.Palo Alto: Consulting Psychologists Press, 1981.

MASLACH, C.; SCHAUFELI, W. B.; LEITER, M. P. Job Burnout.Annual Review of Psychology, Palo Alto, v. 52, n. 1, p. 397-422, 2001.Disponível em: < http://www.annualreviews. org/doi/pdf/10.1146/annurev.psych.52.1.397 > . Acesso em: 15 fev. 2016. 
MELO, W.F; REGO, S.M.O; SALDANHA, H.G.A.C; OLIVEIRA FLOR, M. F.P; MARACAJA, P.B. Síndrome de Burnout em Professores. Revista Brasileira de Educação e Saúde, Paraíba, v. 5, n. 4, p. 01-06, 2015. Disponível em: < http://gvaa.com.br/revista/index. php/REBES/article/view/3651/3290>

NÓBREGA, C. B.; BARBOZA, P. O fonoaudiólogo adoece: síndrome de Burnoute fonoaudiologia hospitalar - uma revisão. Revista CEFAC, São Paulo, v. 16, n. 3, maio/jun. 2014. Disponível em: < http://www.scielo.br/pdf/rcefac/v16n3/1982-0216rcefac-16-3-0985.pdf>. Acesso em: 15 fev. 2016.

PIRES, D. A.; SANTIAGO, M.L.M., SAMULSKI, D.M., COSTA, V.T. A síndrome de Burnoutno esporte brasileiro. Revista da Educação Física, Maringá, v. 1, n. 23, p. 131-139, 2012. Disponível em: < http://periodicos.uem.br/ojs/index.php/RevEducFis/ article/view/14566/9341 >. Acesso em: 15 fev. 2016.

PIRES, D. A; BRANDÃO, M. R. F; SILVA, C. B. Validação do questionário de Burnout para atleta. Revista da Educação Física, Maringá, v. 17, n. 1, p. 27-36, 2006. Disponível em: < http://dx.doi.org/10.4025/reveducfisv17n1p27-36>. Acesso em: 15 fev. 2016.

RUDNICKI, T.; CARLOTTO, M. S. Formação de estudante da área da saúde: reflexões sobre a prática de estágio. Revista Sociedade Brasileira de Psicologia Hospitalar,Belo Horizonte, v. 10, n. 1, p. 97-110. 2007. Disponível em: < http://pepsic.bvsalud.org/ pdf/rsbph/v10n1/v10n1a08.pdf>. Acessoem: 15 fev. 2016.

SCHAUFELI, W. B., SALANOVA, M., GONZÁLEZ-ROMÁ, V.; BAKKER, A.The measurement of burnout and engagement: A confirmatory factor analytic approach. JournalofHappinessStudies, Holanda, v.3,p. 71-92, 2002.Disponível em : < http://www. wilmarschaufeli.nl/publications/Schaufeli/178.pdf>acesso em: 15 fev. 2016

SILVA, G. N.; CARLOTTO M. S. Síndrome de Burnout: um estudo com professores da rede pública. Revista Psicologia Escolar e Educacional, Uberlândia, v. 7, n. 2, p. 145-153, 2003. Disponível em: < http://www.scielo.br/pdf/pee/v7n2/n2a04.pdf> . Acesso em: 15 fev. 2016.

TARNOWSKI, M.; CARLOTTO, M. S. Síndrome de Burnout em estudantes de Psicologia. Temas em psicologia, Ribeirão Preto, v. 15, n. 2, p. 173-180, 2007. Disponível em: < http://pepsic.bvsalud.org/pdf/tp/v15n2/04.pdf>. Acesso em: 15 fev. 2016.

TOMASCHEWSKI-BARLEM, J. G.; LUNARDI, V.L.; RAMOS, A.M.; SILVEIRA, R.S.; DEVOSBARLEM, E.; ERNANDES, C.M.Manifestações da Síndrome de Burnoutentre Estudantes de graduação em enfermagem. Texto \& Contexto Enfermagem, Florianópolis, v. 22, n.3, p. 754 -62, 2013. Disponível em: < http://www.scielo.br/pdf/tce/v22n3/v22n3a23. pdf $>$. Acesso em: 15 fev. 2016.

TRIGO, T. R.; TENG, C.T.; HALLAK, J. E. C. Síndrome de Burnoutou estafa profissional e os transtornos psiquiátricos. Revista de Psiquiatria Clínica, São Paulo,v. 34, n. 5, p. 223-233, 2007. Disponível em: < http://www.scielo.br/pdf/rpc/v34n5/a04v34n5. pdf >. Acessoem: 15 fev. 2016.

Recebido em: agosto/2016

Aprovado em: abril/2017 